\title{
Sustainability Assessment in Sub Saharan African Communities, With Emphasis on Green House Effects and Climate Change
}

\author{
Ebenezer Yiwo $^{1}$, Daniel Jato-Espino ${ }^{1,2}$, Marta Vila-Cortavitarte ${ }^{1,2}$ \\ ${ }^{1}$ Green Fortland Foundation \\ Post Box 105, Prestea, Ghana \\ me.joe22@yahoo.com; greenfortlandfoundation@gmail.com \\ ${ }^{2}$ University of Cantabria, School of Civil Engineering \\ Av. De los castros 44, 39005 Santander, Spain \\ Daniel.jato@unican.es; marta.vila@unican.es
}

\section{Extended Abstract}

The natural inter dependency between mankind and the environment is speedily on the decline in the sub-Saharan zone due to some human activities. It does require energy, innovation via research and in-depth education on the consequences of global warming to address the menace on the environment (1). Human population increases directly with the increasing green - house effects and climate, especially in the form of global warming due to human activities (2). The green nature of sub Saharan Africa (3) has greatly been tempered with in recent times. Activities such as unregulated local refinery, illegal mining, legal mining, industrial burning processes (4), permission and use of old engines (highly polluting vehicles) and the replacements of green coverings with unsustainable urban fabrics (5). These activities influence deforestation, desertification, and pollution in air, water and land. Furthermore, some high profiled people become the promoters and somehow master minders of such acts for their financial interests. In this contest, this research seeks to develop a methodology to determine the degree of sustainable development goals (6), with emphasis on the greenhouse effect and climate change. To this end, a literature will be conducted to get insight into the potential impacts of green house gases and climate change in these regions in comparison with other continents (7). Then, Geographic Information Systems (GIS) will be applied to explore the relationships between these effects and the societal and developmental growth. The proposed approach will be validated by collecting data required for its application to Ghanaian communities, due to the representativeness of this country in terms of human- induced green house gases and climate change (8).

\section{References}

[1] D. K. Inkoom, "Climate change and poverty in ghana," Issues and implications for policy. Regional Development Dialogue, vol. 32, no. 1, pp. 35-50, 2011.

[2] J. K. Assan, "Environmental variability and vulnerable livelihoods: Minimising risks and optimising opportunities for poverty alleviation," Journal of International Development, vol. 21, no. 3, pp. 403-418, 2009.

[3] C. B. Wiederkehr, "Environmental change, adaptation strategies and the relevance of migration in sub-saharan drylands," Environmental Research Letters, vol. 13, no. 11, 2018.

[4] X. G. Wang, "A nexus approach for sustainable urban energy-water-waste systems planning and operation," Environmental Science and Technology, vol. 52, no. 5, pp. 3257-3266, 2018.

[5] A. A. Dawodu, "A conceptual re-visualization of the adoption and utilization of the pillars of sustainability in the development of neighbourhood sustainability assessment tools," Sustainable Cities and Society, vol. 28, pp. 398-410, 2017.

[6] A. Omisore, "Attaining sustainable development goals in sub-saharan Africa; the need to address environmental challenges," Environmental Development, vol. 10, pp. 138-245, 2018.

[7] N. K. Yakovleva, "Reflections on the opportunities for mining companies to contribute to the united nations sustainable development goals in sub - saharan africa," Industries and Society, vol. 4, no. 3, pp. 426-433, 2017.

[8] S. Opare, "Adaptation toclimate change impacts: coping strategies of indigenous community in Ghana to decline water supply," Climate and Development, vol. 10, no. 1, pp. 73-83, 2018. 